ГАДЖИЕВ Камалудин Серажудинович - доктор исторических наук, профессор, главный научный сотрудник Национального исследовательского института мировой экономики и международных отношений им. Е.М. Примакова РАН (117997, Россия, г. Москва, Профсоюзная ул., 23; k.zuhrabvi@ gmail.com)

\title{
О ТОТАЛИЗАЦИИ ВОЙНЫ В ГИБРИДНОМ ИЗМЕРЕНИИ
}

\begin{abstract}
Аннотация. В статье предпринята попытка выявить и проанализировать основные факторы и вехи тотализации конфликтов и войн в современном мире в ее тесной связи с так называемым гибридным их типом. Главное внимание концентрируется на особенностях, системных и структурных составляющих, направлениях и конкретных проявлениях тотализации в условиях глобализации и информационной революции. Автор дает анализ установок и проектов завоевания власти на национальном и глобальном уровнях путем установления культурной, идеологической, идеолого-информационной гегемонии. Должное место уделено таким ключевым аспектам и механизмам тотализации, как "мягкая сила", ее соотношение с «жесткой силой», гибридные войны, кибервойны, санкции и некоторые ответвления международного терроризма, стратегия экспорта так называемой демократической революции и др. Сделан вывод, что тотализация взаимного страха, недоверия, противоречий, конфликтов, войн, широкомасштабно и глубоко охватив важнейшие сферы бытования всех государств и народов, приобрела беспрецедентные масштабы и необратимый характер.
\end{abstract}

Ключевые слова: конфликт, война, тотализация, тотальная война, гибридная война, геополитика, глобализация, информационная революция, культурная гегемония, «мягкая сила», “жесткая сила»

\section{О симбиозе «мягкой» и «жесткой» силы в феномене тотализации войны}

Когда 9 ноября 1989 г. пала Берлинская стена, многие уповали на то, что в Европе, да и во всем мире, наступит, наконец, период всеобщей гармонии и порядка, мира и согласия между народами. Сложилось убеждение, согласно которому тенденция к утверждению демократии во все более растущем числе стран и регионов постепенно приведет к коренному изменению самой природы внутри- и внешнеполитических отношений во всемирном масштабе. Главным же ее результатом, по мнению многих исследователей и наблюдателей, станет исчезновение войн из жизни человечества в силу формирования международной системы, основанной на фундаментальной социальной, экономической, политической, идеологической трансформации современного мира на путях рыночной экономики и политической демократии. Появилось множество работ, лейтмотивом которых стал тезис, что в современную эпоху по мере утверждения во всем мире западной модели политической демократии разного рода межгосударственные и иные конфликты и войны становятся достоянием истории.

Однако реалии современного мира опровергают подобные надежды. С сожалением приходится констатировать, что одновременно с увеличением числа государств, как будто вставших на рельсы демократического развития, парадоксальным образом на поверхность вышли дремлющие силы межобщинных, этнических, трайбалистских, клановых, конфессиональных и иных приверженностей и ксенофобий. Они служат питательной почвой для развязывания этнических и территориальных конфликтов, гражданских, религиозных и межгосударственных войн, которые в условиях глобализации и информационнотелекоммуникационной революции приобретают новые по сравнению даже с недавним прошлым формы.

Одним из знаковых их проявлений является качественно новый уровень тотализации войны, приобретающей гибридные формы. Разумеется, сам феномен 
тотализации коренится в истории. Известный немецкий военный теоретик XIX в. К. фон Клаузевиц назвал возникавший в его время новый тип войны «абсолютной войной», ставшей прототипом тотальных войн XX в. Впрочем, исторические корни тотальной войны - весьма объемная и сложная тема, требующая самостоятельного исследования. Здесь главное внимание концентрируется именно на тотализации войны в условиях информационной революции и глобализации.

В широком смысле, если исходить из опыта Второй мировой войны, под тотальными понимаются войны, в которые вовлечены не только многочисленные армии, но и множество народов, государств, регионов, в которых почти полностью стираются границы между вооруженными силами и мирным населением, между фронтом собственно военных действий и тылом. Театром военных действий становятся, по сути дела, все пространства, занятые народами и государствами, вовлеченными и в определенной степени не вовлеченными в военные действия. Существенно возрастает радиус действия военной авиации, подводный флот приобретает всевозрастающую роль в борьбе с надводным флотом. Впечатляющие изменения происходят в системах ведения военных действий на суше, что дало возможность одерживать широкомасштабные молниеносные победы, которые не могли даже сниться Александру Македонскому, Цезарю, Наполеону и даже воюющим державам во время Первой мировой войны. Речь идет о грандиозных победах, одержанных вермахтом в первой половине войны, и не менее впечатляющих победах, которых добились союзники над странами оси во второй половине войны.

Отсюда такие ставшие привычными при характеристике Второй мировой войны понятия, как тотальная война, тотальная мобилизация, безоговорочная и полная капитуляция, победа любой ценой и т.д. Что отличало Вторую мировую войны от всех предыдущих войн, так это одержимость всех, и военных, и гражданских, мыслью о победе во что бы то ни стало, победе любой ценой. В самом намерении начать и вести войну имплицитно заложен принцип, согласно которому цель оправдывает средства. Свое законченное выражение получил постулат о том, что победителей не судят. Оборотной стороной такой одержимости стал прямо-таки экзистенциальный страх потерпеть поражение и расплатиться за последствия войны. В результате для всех сторон компромисс стал как бы признаком неудачи и поражения, Карфагенский мир стал лозунгом дня, который получил легитимность благодаря решениям Нюрнбергского процесса.

Информационно-телекоммуникационная революция и глобализация и связанные с ними тектонические сдвиги в важнейших инфраструктурах современного мира привели к качественным изменениям в понимании и трактовке конфликтов и войн, их системных и структурных составляющих, их новых типов, в условиях и принципах осуществления и т.д. Стало очевидным, что в современных условиях важнейшие характеристики и приоритеты мировой политики не всегда и не обязательно определяются и трансформируются при помощи бомб и штыков, через военные триумфы и капитуляции.

В этом русле прежде всего обращает на себя внимание феномен так называемой «мягкой силы» (soft power). Она охватывает весь комплекс ресурсов, средств государства, не связанных с военной, или «жесткой» силой (hard power), но теснейшим образом связанных с ней и дополняющих ее. Если «жесткая сила» имеет своей целью запугать и наказать противника с помощью оружия, то «мягкая сила» призвана привлечь его на свою сторону или, во всяком случае, нейтрализовать его мирными, бескровными, как говорится, не летальными средствами и методами. В ее основе лежат культура и ценности, идеи, символы, мифы и т.д. 
«Когда ты можешь побудить других возжелать того же, чего хочешь сам, - писал один из разработчиков этой концепции американский политолог Дж. Най, тебе дешевле обходятся кнуты и пряники, необходимые, чтобы двинуть людей в нужном направлении. Соблазн всегда эффективнее принуждения, а такие ценности, как демократия, права человека и индивидуальные возможности, глубоко соблазнительны. Но влечение может обернуться и отвращением, если в политике чувствуется надменность или лицемерие» [Най 2004].

В этом русле все возрастающую актуальность приобретают новейшие виды войн, такие как экономическая, торговая, экологическая, информационная и т.д. Новое измерение и новый импульс приобретают идеологическая, пропагандистская, психологическая и иные разновидности бескровных войн. Все более растущее значение приобретают вопросы, касающиеся условий торговли, потока ресурсов - капиталов, технологий, товаров, услуг и т.д. Все чаще споры между государствами решаются с помощью процентных ставок, курсов валют, конкурентоспособности национальной экономики на мировых рынках и т.д. Кардинальные перемены порою заявляют о себе безо всяких видимых сенсаций, или, иначе говоря, на геополитическом горизонте так называемые черные лебеди могут появляться как бы неожиданно для всех субъектов мировой политики.

Наблюдается тенденция к возрастанию роли культурного, информационноидеологического компонента в мировой политике, прежде всего во внешнеполитической стратегии великих держав. Беспрецедентно возросло влияние культуры на общемировые социально-экономические процессы, на характер межгосударственных отношений; она стала одним из действенных инструментов внешней политики и эффективным средством борьбы за национальные интересы. Корни таких тенденций восходят к теории культурной гегемонии, которая была разработана одним из основателей и идеологов Коммунистической партии Италии А. Грамши еще в 30-х гг. прошлого века. Суть ее заключалась в том, что для победы в борьбе за политическую власть необходимо прежде всего завоевать гегемонию на культурном пространстве. Понятия «культурное доминирование», «культурная гегемония», «культурное господство» заняли соответствующее место в геополитическом лексиконе, усиливая идеологическую составляющую глобального информационного пространства. Культурная экспансия стала одним из ключевых атрибутов имперской власти, важнейшим инструментом рекламирования и распространения соответствующих ценностей, институтов, образа и философии жизни, представлений о будущем.

Следуя этой установке, руководства стран Запада, прежде всего США, стремятся сохранить и расширить свои господствующие позиции на мировом культурном и информационно-идеологическом пространстве. Как отмечал бывший служащий администрации президента США У. Клинтона Д. Роткопф, «в эпоху информационных технологий главной задачей внешней политики Соединенных Штатов должна стать победа на рынке мировых информационных потоков. США должны добиться доминирования, подобного тому, которым когда-то обладала Великобритания на море». В такой политике Роткопф усматривал благо не только для самой Америки, но и всего остального мира. «То, что хорошо для Соединенных Штатов Америки, - утверждал он, - хорошо для всего человечества!» [Rothkopf 1997: 40].

При оценке этих реалий нельзя забывать тот очевидный факт, что во все времена верх одерживали идеи, которые подкреплялись силой; побеждали вооруженные пророки, которые были способны привлечь силу для реализации своих идей. В современных условиях реальная «жесткая сила» не потеряла свое значение в качестве ключевого ресурса государства, обеспечивающего его геополи- 
тический статус и влияние в мире. Более того, в складывающихся в последние десятилетия условиях фактор «жесткой силы» в новых формах и проявлениях приобретает все более растущую значимость.

\section{О гибридных войнах}

Исходя из этого, естественно, имеет место тенденция к симбиозу «мягкой» и «жесткой» силы, который получил наиболее законченное выражение в так называемой гибридизации войны или, проще говоря, в гибридных войнах. Несмотря на весьма недолгий период существования данного понятия, оно прочно утвердилось не только в научной и публицистической литературе, в средствах массовой информации и политической практике, но также в официальных документах, отражающих политику и поведение государств на международной арене. Так, на встрече Совета министров иностранных дел НАТО, состоявшемся 1 декабря 2015 г. в Брюсселе, впервые принята Стратегия гибридных войн. Как отметил генеральный секретарь НАТО Й. Столтенберг, «гибридная война охватывает широкий перечень различных типов военных действий... Этот термин используют для описания сочетания военных и невоенных средств, скрытых и открытых операций... Это комбинация различных гражданских и военных приемов». По его словам, примером гибридной войны являются действия России, приведшие к «аннексии Крыма», а также ее действия в Донбассе ${ }^{1}$.

С этой точки зрения интерес представляет позиция начальника Генерального штаба Вооруженных сил Российской Федерации В.В. Герасимова, который в еженедельнике «Военно-промышленный курьер» в феврале 2013 г. заявил, что в XXI в. войны, которые он назвал гибридными, опираются на нетрадиционные «асимметричные» средства с целью создания «постоянно действующего фронта на всей территории противостоящего государства». По его мнению, в этих войнах «возросла роль невоенных способов в достижении политических и стратегических целей, которые в ряде случаев по своей эффективности значительно превзошли силу оружия». Их особенность, согласно Герасимову, состоит в «тенденции стирания различий между состоянием войны и мира. Войны уже не объявляются, а, начавшись, идут не по привычному нам шаблону». В качестве типичного примера таких войн он привел «цветные революции» на Ближнем Востоке и в Северной Африке 2 .

Любые войны - результат политических решений для достижения политических целей. В этом смысле гибридные войны вовсе не отменяют фундаментальные причины, природу, цели традиционных войн. Сутью войн и новейших вооруженных конфликтов, как и прежде, остается борьба за власть. Их «творцами» и «драйверами» выступают политические элиты государств, а сама война остается продолжением политики другими средствами. Вместе с тем для современных конфликтов характерны такие черты, как участие негосударственных акторов, наемничество, приватизация насилия, этнические и религиозные противоречия, сочетание новейших и самых архаичных средств противоборства, новых форм и средств, которые выходят за рамки традиционного облика войны. Важная роль при этом придается методам, сочетающим поддержку существующих вооруженных конфликтов, идеологическую агрессию, экономические санкции, попытки политической изоляции с поиском новых внутриполитических уязвимостей, применением передовых информационных технологий, давлением на союзников и так называемые третьи страны. Применяется

\footnotetext{
1 Полунин А. НАТО: курс на гибридную войну. Доступ: https://www.discred.ru/news/nato_kurs_na_ gibridnuju_vojnu/2015-12-01-17484 (проверено 30.04.2019).

2 Акопов П. 2018. Здание западной русофобии начало рушиться. Доступ: https://vz.ru/ politics/2018/3/10/911616.html (проверено 30.04.2019).
} 
весь спектр доступных военных и невоенных форм, средств, методов и технологий идеологического, информационного, культурного, экономического, геоэкономического, политического, геополитического и иных проявлений противоборства.

Ареной гибридных войн стало киберпространство, на котором разворачиваются бескровные, напрямую не обязательно связанные с человеческими жертвами, но чреватые серьезными непредсказуемыми последствиями войны. Одним из важнейших средств в этих войнах служит распространение так называемых фейковых новостей. Немаловажное значение придается пропаганде, кибератакам, информационно-идеологическим диверсиям, таким, например, как казус Литвиненко и Скрипаля. Разрабатываются кибербомбы, цифровые бомбы, внедряемые в компьютерные сети противника для парализации его жизненно важных промышленных объектов, систем политического, экономического и военного управления.

Здесь главными агентами выступают не только государства, но также отряды взломщиков или просто одиночные взломщики, которые, приобретая все более расширяющиеся знания и опыт вывода из строя оборонных и гражданских объектов, способны привести в замешательство целые государства и народы. Получает все более широкое распространение так называемый информационный, или хакерский терроризм, нацеленный на взлом банковских кодов и внедрение вирусов для вывода из строя компьютерных систем и созданных на их основе банковских, биржевых, исследовательских, управленческих и иных структур, что чревато катастрофическими последствиями для тех или иных объектов народного хозяйства.

Можно утверждать, что кибервойны носят многоликий, многовекторный, многополярный характер, который, в свою очередь, еще более осложняется в силу их виртуальности. Здесь много субъектов, конфликтующих и воюющих друг с другом, что делает весьма трудным, если не невозможным, определение источника угрозы и агрессии. Они не поддаются контролю, против них пока что бессильны традиционные военные средства и методы, самые совершенные, высокоточные межконтинентальные ядерные ракеты. Одним из первых более или менее серьезных примеров их использования в мировом масштабе стала кибератака 12 мая 2017 г., когда так называемый вирус-вымогатель WanaCryptOr 2.0 заразил десятки тысяч компьютеров в 74 странах по всему миру, парализовав работу британских больниц и испанских компаний, атаковав в России региональные управления МВД и Следственного комитета. Масштабные кибератаки становятся чуть ли не повседневным событием. Поэтому естественно, что создаются соответствующие структуры обеспечения кибербезопасности.

Выведя за скобки множество аспектов, которые в должной мере не разработаны в отечественной и зарубежной геополитике, в качестве одного из проявлений гибридной войны в данной сфере считаю уместным обратить внимание на экономические санкции. Их в полной мере можно назвать именно санкционной войной, ведущейся той или иной страной или группой стран против страны-противника для разрушения ее экономики и, соответственно, подавления воли противника к сопротивлению. Санкции стали серьезным и все более часто используемым средством политического и экономического давления на противника. Развязанная Западом против России в качестве ответа на ее противодействие экспансии НАТО, такая война рассматривается как средство подавления ее воли и изоляции, как бы в наказание за воссоединение с Крымом и поддержку стремления народа Донбасса защищать свои жизненно важные интересы. Перефразируя знаменитую формулу К. фон Клаузевица «война есть продолжение политики другими средствами», можно утверждать, 
что санкции - это форма развязывания и ведения «холодной войны» другими средствами.

У США (в меньшей степени - у Запада в целом) формируется (или уже окончательно сформировался) комплекс санкционной зависимости в качестве своего рода универсального средства борьбы с противником. В этом контексте симптоматично утверждение министра финансов при президенте Б.Х. Обаме Дж. Лью: санкции «стали мощной силой на службе у ясных и скоординированных внешнеполитических целей» 1 .

Как показывают современные мировые реалии, великие суверенные, особенно ядерные, державы по определению не способны с помощью будь то санкций или каких-либо иных средств изолировать или сдерживать друг друга, тем более одерживать победу друг над другом. При наличии политической воли санкции могут стать стимулом для развития, во всяком случае тех отраслей экономики, которые зависят от импорта новейших технологий, иностранных инвестиций, а также экспорта той или иной отечественной продукции. Обоснованность данного тезиса подтверждается на примере России, которая в условиях все возрастающей санкционной политики Запада сумела решить целый ряд проблем импортозамещения и добиться заметных успехов в ослаблении зависимости экономики от экспорта энергоресурсов.

По-видимому, в рассматриваемом русле, разумеется, не без определенных оговорок, в качестве еще одного проявления тотализации и гибридизации войны следует рассматривать некоторые ответвления терроризма, которые обосновываются лозунгами экспорта исламской революции. Эта тема вроде бы вдоль и поперек исследована в отечественной зарубежной научной литературе. Здесь представляется уместным отметить лишь тот факт, что современный международный терроризм выступает в роли своеобразного параллельного анонимного субъекта мировой политики, способного оказывать существенное влияние на магистральные тенденции геополитического развития современного мира.

Или, иначе говоря, начала вырисовываться новая универсальная тенденция выхода на геополитическую авансцену качественно нового феномена - самостоятельных военизированных структур и систем, не связанных с конкретными национальными государствами или государственными институтами, которые стали своего рода теневыми транснациональными сообществами, способными оказывать существенное влияние на магистральные тенденции геополитического развития. По сути дела, выступая для многих государств в качестве анонимного «врага без границ», они служат зримым доказательством того, что государство теряет свою монополию на вооруженное насилие для обеспечения своей национальной безопасности. Речь идет о своеобразной «денационализации» насилия, своего рода приватизации права и средств применения насилия, призванного вызвать страх и панику. В результате право войны и мира перестало быть монополией государства. Это право явочным порядком взяли на себя негосударственные организации и группировки. Это, например, носители и проповедники новой «культуры Калашникова», основанной на оправдании вооруженного насилия, призванного вызвать массовый страх и панику населения целых государств и даже регионов.

Сила и опасность этого своеобразного агрессивного «мирового подполья» состоит в том, что оно, действуя на стыке рационального и иррационального, не признает какие бы то ни было установившиеся на государственном и надгосударственном уровнях общепринятые морально-этические и правовые

\footnotetext{
${ }^{1}$ Bhatia N., Saravalle E. America Is Addicted to Sanctions. Time for an Intervention. - The Atlantic. 2018. August 5.
} 
нормы и ограничения. К примеру, если у государственных акторов, хотя и в разной степени, сохраняется некий международно-правовой, моральный, психологический и иные барьеры, которые они не могут преодолеть, то для террористов такой барьер напрочь отсутствует. Навязываемая ими война, которая должна вестись по периметру в $360^{\circ}$, принимает мимикрированные, мутагенные формы, асимметричный характер, обусловленные различиями в военных, экономических, финансовых и технических возможностях участвующих в конфликте сторон.

Возможно, мы имеем дело с разновидностью феномена, ставшего одним из составных элементов тотализации, который в научной литературе получил название «малая война». Как отмечал немецкий исследователь М. Гох, «малая война по определению не знает границ, все средства пускаются в ход, и с характерной для нее брутальностью, в особенности по отношению к мирным жителям, женщинам и детям, она приобретает черты, сближающие ее с феноменом тотальной войны, а именно: в качестве врага рассматривается весь совокупный противник, который становится объектом боевых действий, а не только его вооруженные силы... Для малой войны типично сознательное стремление наносить удары по наиболее ранимым, чувствительным сторонам врага, именно по мирным жителям» [Hосh 2001: 19]. Очевидно, что, если даже это «малая война», она укладывается в комплекс тотализции взаимных страхов, угроз, ответов, претензий, конфликтов, войн на глобальном уровне.

Можно утверждать, что современный терроризм по своим целям, методам и средствам осуществления представляет собой в некотором роде одно из проявлений асимметричного ответа на агрессивное наступление западных социокультурных, политико-культурных, демократических ценностей и принципов, самого западного образа жизни.

Войны в современных условиях органически сочетают в себе регулярные (или так называемые симметричные) боевые действия и «асимметричные», или скрытые средства, методы, такие как диверсии, кибератаки, пропаганда и дезинформация в форме так называемых фейковых новостей, широкая поддержка внутренней оппозиции в качестве троянского коня, повстанцев, партизан, а то и открытых террористических действий на территории противника.

Асимметричный компонент в современных войнах стал иметь гораздо более выраженный, часто - решающий характер. Во многих из этих войн так называемые партизаны, повстанцы, просто террористы потеряли свой национально ориентированный характер, зачастую превратившись в своего рода марионеток в руках внешних кукловодов.

В асимметричных войнах, какими являются в т.ч. войны террористические, победа не всегда и не обязательно предрешена в пользу сильнейшего. Их особенность состоит в том, что «маленькая победоносная война», затеваемая той или иной великой державой в полном убеждении, что победа ее оружия обеспечена малыми жертвами, может превратиться в затяжной, дорогостоящий кровопролитный конфликт, который в конечном счете может обернуться поражением. Опыт американо-английской агрессии против Ирака показал, что военная операция в предельно ослабленном экономическими санкциями государстве, по сути дела, продемонстрировала бессилие беспрецедентной мощи самой могущественной державы современного мира. Вскоре после начала агрессии в Ираке в 2003 г. тогдашний президент США Дж. Буш-младший, констатируя разгром иракской армии и ликвидацию режима Саддама Хусейна, декларировал триумф победоносных вооруженных сил США. Всем известно, чем обернулся этот триумф: одержав победу в битве, Америка потерпела сокрушительное поражение в войне. За молниеносной военной победой, одержанной в 2003 г. 
американской армией в Ираке, последовал постепенно набиравший силу хаос, который превратил эту страну, до этого весьма далекую от нестабильности и тем более от террора, в плацдарм международного терроризма. Обнаружилось, что, одержав победу в битве, самая могущественная военно-политическая и экономическая супердержава современного мира продемонстрировала свою неспособность обеспечить контроль над стремительно набиравшим силу хаосом и, по сути дела, проигрывает войну.

Партизанская война, разного рода радикальные и радикалистские акции, в т.ч. терроризм, наркобизнес, транснациональная преступность, контрабанда и т.д., - это явления такого порядка, которые весьма трудно, если не невозможно устранить с помощью военной силы. Высокоточное оружие, возможно, более «гуманно», если здесь приемлемо это выражение, но оно не может служить универсальным средством отражения новых вызовов, порожденных новыми реалиями века глобализации и информационно-телекоммуникационной революции. Попытки нанести им поражение или уничтожить их традиционными средствами подобны стрельбе из пушек по воробьям. Возможно, при этом пострадает определенное число конкретных воробьев, но само семейство воробьев таким образом не уничтожить. Точно так же в результате массированных бомбардировок высокоточным оружием городов возмездие редко настигает реальных виновников преступления. Такие бомбардировки могут поразить те или иные убежища террористов, но не способны уничтожить терроризм.

\section{Ядерное оружие в контексте гибридизации и тотализации войн}

Особо важное значение с рассматриваемой точки зрения имеет тот факт, что сдерживающая роль, которую играло в XX в. наличие ядерного оружия, претерпевает определенные метаморфозы в том смысле, что подвергается, возможно, подсознательной, но все возрастающей переоценке табу на его использование как шаг к самоуничтожению человечества. Иначе говоря, в некотором роде принцип гибридизации распространяется и на ядерное оружие.

В период двухполюсной конфронтации между Востоком и Западом действовал определенный комплекс признанных и в целом соблюдаемых обеими сторонами норм, правил политического поведения. Обе стороны знали, кто друг, и кто враг, кто союзник, и кто противник, где именно пролегают те красные линии невозврата, или рубиконы, которые рассматривались обеими сторонами как точки невозврата и которые поэтому ни при каких обстоятельствах нельзя пересекать. Через всю «холодную войну» периода двухполюсного миропорядка красной нитью проходило понимание необходимости соблюдения этого правила. При всех возможных оговорках две противоборствующие стороны были склонны к взаимным компромиссам по ключевым вопросам международной и национальной безопасности. Было ясное понимание, что ядерная война это акт безумия, ведущий человечество к самоуничтожению. Возможно, не случайным представляется тот факт, что выражение «гарантированное взаимное уничтожение», которое на английском языке передается как mutual assured destruction, в аббревиатуре выражается как MAD. Соответственно, слово mad на русский переводится как «безумный». Практически обеими противоборствующими сторонами возможность использования этого вооружения оценивалась как акт безумия.

Иное положение складывается в наши дни. Наблюдается тенденция к девальвации такого понимания ядерной войны. Имеют место попытки пересмотра идеи гарантированного взаимного уничтожения, которая лишает смысла любую ядерную войну. По словам бывшего главы делегации США на переговорах с СССР по СНВ-1 Р. Берта, американские политики рассматривают возможность 
вести ядерную войну и выйти из нее победителем за счет применения новых вооружений и технологий ${ }^{1}$. В частности, в 2018 г. США приняли на вооружение новую доктрину точечных «избирательных ударов», которая подразумевает возможность небольшой ограниченной военной операции с использованием миниатюрных ядерных зарядов или применения так называемого тактического ядерного оружия против противника. В результате красные линии, рубиконы оказываются как бы размытыми, теряют былую значимость, становятся, условно говоря, пересекаемыми, во всяком случае, в сознании тех или иных государственных деятелей, военачальников, особенно пишущей братии.

Очевидно, что возможность применения ядерного оружия подвергается детабуизации, приобретая все возрастающее число сторонников, особенно из числа новых поколений политиков, представителей политической, интеллектуальной, медийной элиты. Начальник Объединенного штаба генерал Брэдли относительно корейской войны произнес ставшую знаменитой фразу: схватка всеобщего характера по поводу Кореи «вовлечет нас не в ту войну, не в том месте, не в то время и не с тем противником» [Киссинджер 1997: 439]. Те тенденции и процессы, которые характерны для мировой политики в современном мире, могут привести великие державы именно к этой ситуации.

При биполярном миропорядке границы между двумя блоками, или полюсами, были четкими, жесткими, непроницаемыми. Все было более или менее ясно: где границы, разделяющие два мира, где «мы», и где «они», где враги, и где друзья, кто свой, и кто враг, кто наступает, и кто обороняется, кто одержал победу, а кто потерпел поражение, какие именно силы стоят за каждой из воюющих сторон.

По-иному обстоит дело в современных условиях, когда имеют место гибридные войны. Во все более растущей степени размываются границы между угрозами национальной безопасности и международной безопасности. Стало весьма трудным, а то и невозможным делом определить конкретный и сколько-нибудь четко обозримый и прогнозируемый источник угрозы национальной безопасности, ее ассоциацию с конкретной страной или группой стран. В ней нет очевидных фронтов и строго очерченного круга участников, нет линии фронта, поскольку она пролегает повсеместно, в результате чего оказывается призрачной. Соответственно, размываются линии разграничения между внутренними и внешними угрозами национальной безопасности, между войной и миром, государственным переворотом и революцией, дозволенным и недозволенным, между защитниками и разрушителями международного права и т.д.

В результате если войны, которые раньше имели место в Европе, некоторые авторы называли «европейскими гражданскими войнами», то теперь все более убыстряющиеся глобализация и универсализация мира, его дальнейшее сжатие и закрытие создают условия, которые позволяют говорить о гражданских войнах мирового масштаба, о всемирных гражданских войнах в форме, например, партизанской или террористической войны, за которой, естественно, следует антипартизанская или антитеррористическая война, которые во все возрастающей степени приобретают всемирный, глобальный характер. В том же направлении развиваются организованная преступность, контрабанда живого товара, наркобизнес и т.д.

Тотализация в этом разрезе приобретает особую значимость в силу того, что нередко войны и конфликты оказывались и оказываются наиболее опустошительными не столько на разломах цивилизаций или между различными циви-

\footnotetext{
1 Зайнашев Ю., Нечаев А. Почему США верят в маленькую победоносную ядерную войну. 17.04.2019. Доступ: https://vz.ru/politics/2019/4/17/973566.html?utm_source=yxnews\&utm_medium=desktop (проверено 30.04.2019).
} 
лизациями, сколько в пределах одной и той же цивилизации, одной и той же страны, одного и того же народа, между соседними, зачастую близкими по крови, культуре, языку народами. Или, иначе говоря, как показывает исторический опыт, особой ожесточенностью и жестокостью характеризуются гражданские войны.

Можно в чем-то согласиться с теми авторами, которые убеждены в невозможности тотальной войны в современном мире, разумеется, если игнорировать противоречивую, амбивалентную природу человека, человеческих сообществ, народов, наций, исповедуемых ими верований, служащих им ориентиром идеалов, миссий и т.д. Homo sapiens, т.е. человек разумный, рационально мыслящий, скорее чаще, чем реже руководствуется импульсами, идущими из самосознания, иррациональными побуждениями, которые оказываются более действенными, нежели рациональные доводы и аргументы. В истории нередко бывали ситуации, периоды, когда в безумие впадали не только отдельно взятый человек или какая-нибудь малая община, а целые народы. В этом контексте с величайшим сожалением приходится констатировать, что ядерное оружие отнюдь не отменило возможность невозможного, поскольку, как показывает исторический опыт, человек и человеческие сообщества часто действовали вопреки очевидному.

Увеличение расстояния, на котором действует оружие убийства, в значительной мере снимает проблемы моральной ответственности, угрызений совести, жалости и других неприятных для убивающего моментов, если, конечно, они возникают. Более того, считается, что изобретение пороха и огнестрельного оружия подорвало не только социальный порядок рыцарской эпохи, но и ее этику. Именно удаленность от результатов во многом делает возможным то, что даже самый безобидный, казалось бы, человек оказывается способным нажать спусковой крючок винтовки или пусковую кнопку носителя оружия массового уничтожения. Все возрастающую значимость приобретает тот факт, что развитие военных технологий способствует постепенной деперсонализации, обезличению военного дела, снижению моральных критериев и усилению тенденций дегуманизации участников военного конфликта, а также уменьшению значения их личного героизма и доблести. Здесь человек приобретает как бы характерологические признаки бездушного, безличного робота, которые лишен каких бы то ни было морально-этических ограничений, симпатий, антипатий, стрессовых состояний и хладнокровно, автоматически выполняет свои функции.

В целом, современные мировые реалии порождают досадное чувство, мягко говоря, неискоренимости человеческих заблуждений, склонности к самообману или сознательному обману при трактовке сложных и весьма трудно объяснимых перипетий, немыслимых зигзагов и загадок, которые История выкидывает изумленному человечеству. Эти заблуждения не стали анахронизмами, а сохранились как вечные, вневременные составляющие человеческой природы.

В этом контексте особенно важно учесть различия между первой и нынешней «холодными войнами», которые состоят в том, что в первом случае руководители каждой из противостоящих друг другу сверхдержав, пережив весь ужас катастрофы Второй мировой войны, несли в себе страх таящихся в ядерном Армагеддоне экзистенциальных последствий для всего человечества. В наши дни проблема состоит в том, что политика, в т.ч. и внешняя политика, полностью перешла к поколению, которое, в отличие от предыдущего поколения, в должной мере не обременено представлениями о реальных ужасах и катастрофических последствиях войны, многим представителям которого войны видятся чуть не некими аналогиями компьютерных игр. 


\title{
Список литературы
}

Киссинджер Г. 1997. Дипломатия. М.: Ладомир. 848 с.

Най Дж. 2004. «Мягкая сила» и американо-европейские отношения. Свободная мысль-ХХІ. № 10. С. 33-41.

Hoch M. 2001. Krieg und Politik im 21. Jahrhundert. - Aus Politik und Zeitgeschichte. Beilage zur Wochenzeitung Das Parlament. 11.05.2001. S. 17-25.

Rothkopf D. 1997. In Praise of Cultural Imperialism. - Foreign Policy. Summer. No. 107. P. 38-53.

GADZHIEV Kamaludin Serazhudinovich, Dr.Sci. (Hist.), Professor, Chief Researcher of the Primakov National Research Institute of World Economy and International Relations, Russian Academy of Sciences (23 Profsoyuznaya St, Moscow, Russia, 117997; k.zuhrabvi@gmail.com)

\section{ON THE TOTALIZATION OF THE WAR IN THE HYBRID DIMENSION}

\begin{abstract}
The article attempts to identify and analyze the main factors and milestones of the totalization of conflicts and wars in the modern world in its close connection with the so-called hybrid type of them. The author focuses the main attention on the features, systemic and structural components, directions and specific manifestations of totalization in the context of globalization and the information revolution and gives an analysis of the attitudes and projects of the conquest of power at the national and global levels by establishing cultural, ideological, ideological and informational hegemony. Due place is given to such key aspects and mechanisms of totalization as soft power, its correlation with hard power, hybrid wars, cyberwar, sanctions and some offshoots of international terrorism, export strategy of the so-called democratic revolution, etc. The author concludes that the totalization of mutual fear, mistrust, conflicts, wars extensively and deeply embracing the most important spheres of existence of all states and peoples, has acquired an unprecedented scale and irreversible nature. Keywords: conflict, war, totalization, total war, hybrid warfare, geopolitics, globalization, information revolution, cultural hegemony, soft power, hard power
\end{abstract}

